\title{
Seismic Performance of Multistorey Masonry Structure with Openings Repaired with CFRP Grid
}

\author{
Jin-Ben Gu, ${ }^{1}$ Yi Tao $\mathbb{D}^{1,2}$ Ren Xin, ${ }^{1}$ Z. Yang, ${ }^{3}$ and Qing-Xuan Shi ${ }^{1}$ \\ ${ }^{1}$ School of Civil Engineering, Xi'an University of Architecture and Technology, Xi'an, Shaanxi 710055, China \\ ${ }^{2}$ State Key Laboratory of Green Building in Western China, Xi'an University of Architecture and Technology, Xi'an, \\ Shaanxi 710055, China \\ ${ }^{3}$ Faculty Research Centre for Built and Natural Environment, Coventry University, Coventry CV1 2JH, UK \\ Correspondence should be addressed to Yi Tao; y.tao@xauat.edu.cn
}

Received 13 November 2017; Revised 1 April 2018; Accepted 15 April 2018; Published 8 May 2018

Academic Editor: Gianmarco de Felice

Copyright (C) 2018 Jin-Ben Gu et al. This is an open access article distributed under the Creative Commons Attribution License, which permits unrestricted use, distribution, and reproduction in any medium, provided the original work is properly cited.

\begin{abstract}
FRP composites have been used for strengthening RC and masonry structures for decades. However, the researches on repairing multistorey masonry structures using FRP grids were relative less. In the present paper, an experimental study on the seismic performance of multistorey masonry structure with openings repaired with CFRP grid is introduced. Specifically, a 1/3-scale three-floor masonry wall with window openings was tested under quasistatic action to simulate the seismic damages. The damaged masonry wall was then repaired by externally bonding CFRP grids to the areas where the cracks intensively occurred. The repaired masonry wall was retested under the same loading to investigate the seismic resistance and assess the recovery attributed from the CFRP grid repairing. The findings of this study showed that CFRP grid repairing could effectively postpone or even prevent the occurrence and development of cracking. The seismic resistance of the masonry, including shear capacity, energy dissipation capacity, deformability, stiffness degradation, and ductility, was restored. The application of CFRP grid may shift the failure mechanism of the multistorey masonry wall. The recommendation of repair scheme for the similar structures was also proposed in accordance with the findings of the present work.
\end{abstract}

\section{Introduction}

There have been large a number of masonry structures still on service although reinforced concrete (RC) and steel structures prevail in the modern structures. Masonry structures show the advantages in good acoustic and heat insulation, local availability of raw material, and low cost $[1,2]$. Masonry is a heterogeneous material because of the diversity of components [3]. The majority of unreinforced masonry (URM) structures are prone to severe damage under seismic action due to the low strength and consequently vulnerable to earthquake [4,5]. URM walls or under-reinforced masonry walls subjected to seismic actions can fail by in-plane or out-of-plane mode. In-plane failures usually exhibit diagonal shear crack pattern, by sliding of a portion of the wall generally along a bed joint, by rocking about the wall toe or by crushing of the wall toe [6]. In terms of the structural configuration, masonry structures, either solid or segmented by window and door openings in each storey, represent the basic structural element of a masonry building [1]. There are two types of failure mechanism summarized by Tomaževič [1] for the masonry wall with openings, weak piers failure, and weak spandrels failure. The masonry structural walls, composed of piers and spandrels, are usually modelled as an equivalent frame structure $[1,7]$. The shear force and bending moment from earthquake are introduced in both piers and spandrels and controls the failure mechanism $[1,8]$.

The application of fiber-reinforced polymer (FRP) for masonry structure retrofitting and repairing is an advanced technology due to its advantages of high strength, light weight, good durability, and convenient implementation [4, 9-13]. In general, the existing studies have demonstrated that the seismic performance, including the seismic shear bearing capacity, the ductility, and the energy dissipation, of masonry structures can be significantly improved by 
bonding FRP composites [4, 14-18]. However, most of the previous studies focused on the FRP strengthened undamaged URM walls. There has been less study contributed to the repairing in which masonry walls were damaged before repairing with FRP. In these repairing studies, the masonry walls were usually subjected to in-plane loading, either quasistatic or shake table testing, to simulate the earthquake actions. These walls were consequently damaged and later repaired with FRP. Then, the repaired walls were tested to failure [13, 19, 20]. The results from Zhou et al. [13] and Santa-Maria and Alcaino [19] suggested that the repair scheme needed to be determined according to the magnitude of damage and proved that the maximum resistance of the repaired walls depended on the repair scheme.

FRP grid is a composite material consisting of bidirectional fibers, which is especially suitable for the structural members with large areas, such as shear walls and slabs [4, 21, 22]. FRP grid has been used to retrofit the RC structures [21, 23]. However, studies on masonry walls repaired with FRP grid have been lack in the literature. Meanwhile, the existing researches are limited to the masonry wallettes [22]. The research on repairing more complex masonry structures, like multistorey masonry walls with openings, is rare.

In this paper, a $1 / 3$-scale three-storey masonry wall with openings was designed. The strength and size of brick and mortar were not scaled accordingly in the present study because it is still a challenge to determine compatible scale factors among structures and materials. The model URM wall initially under the in-plane quasistatic loading was damaged. It was repaired with carbon fiber-reinforced polymer (CFRP) grid, which was adhesively bonded at the areas where the cracks intensively occurred. The repaired masonry wall was retested under the identical loading. The purpose of this work was to investigate the seismic performance of the model wall prior to and after repairing. Comparisons are made in terms of shear strength, cracking pattern, failure mechanism, hysteretic responses, stiffness degradation, energy dissipation capacity, and interstorey drifts. Recommendation of repair scheme for the similar masonry structures was eventually proposed based on the findings of the work.

\section{Experimental Program}

2.1. Model Wall Design. The experiment protocol included the quasistatic testing of the URM wall, repairing the damaged URM wall with CFRP grid, as well as the quasistatic test of the CFRP grids repaired masonry (CRM) wall. A $1 / 3$-scale three-storey masonry wall with openings was constructed. RC beams were set at the top and the bottom of the model wall, to support and apply the uniform vertical load. Three identical openings existed in each floor. RC lintels were set at the top of each opening at the first and second floors, whereas the lintels of third floor overlapped with the top RC loading beam. Both ends of the wall were set with short cross walls, to provide the lateral restriction and accurately model the real multistorey masonry structures. The dimensions of the model wall are illustrated in Figure 1. The repairing scheme was completed by adhesively bonding CFRP grids in the certain areas where the cracks intensively

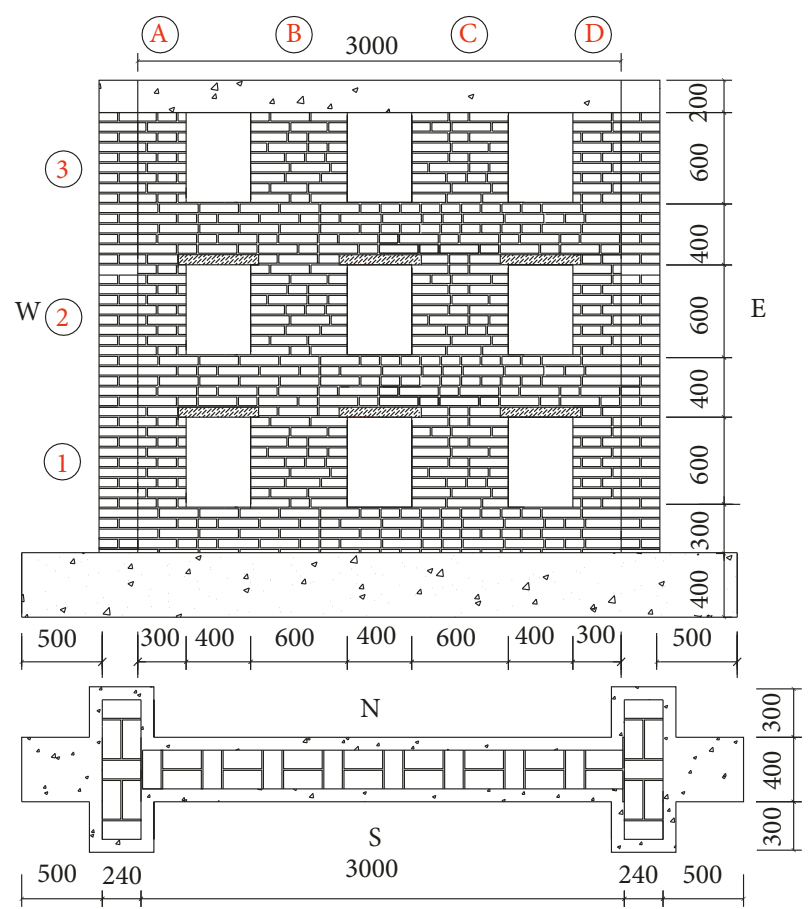

FIGURE 1: Description and Segmentation of multistorey masonry wall $(\mathrm{mm})$ (number-XX represents spandrels and number-X represents piers).

developed. The repairing detail was reported in the following section.

2.2. Material Properties. The model wall was constructed with solid clay bricks $(240 \mathrm{~mm} \times 115 \mathrm{~mm} \times 53 \mathrm{~mm})$. The test brick compressive strength was $17.8 \mathrm{MPa}$ with a standard deviation of $0.12 \mathrm{MPa}$ according to the Chinese standard GB50003-2011 [24]. Twelve cube mortar samples $(70.7 \mathrm{~mm} \times 70.7 \mathrm{~mm} \times 70.7 \mathrm{~mm})$ were cast, and the average compressive strength was $8.6 \mathrm{MPa}$ with a standard deviation of $0.52 \mathrm{MPa}$. Based on the test strengths of brick and mortar, the compression strength and the shear strength of masonry were calculated as $5.3 \mathrm{MPa}$ and $0.37 \mathrm{MPa}$ based on the models proposed in GB50003-2011 [24]. The composite material used in the present study was a bidirectional equal-strength CFRP grid, shown in Figure 2, with uniform grid size of $20 \mathrm{~mm} \times 20 \mathrm{~mm}$ and minimum thread width of $3 \mathrm{~mm}$, for which, the material properties are listed in Table 1. The material properties of the CFRP sheet that were bonded at the edges of openings to prevent the premature cutting fracture of CFRP grid are listed in Table 1. The adopted epoxy adhesive was the Sika-330 epoxy resin, and its material properties are listed in Table 1 as well.

2.3. Test Setup. The test setup is presented in Figure 3. The bottom RC beam was fixed to the strong floor by four threaded rods. Two vertical hydraulic jacks were placed on the top of the distribution beams to apply the vertical load. The top RC beam uniformly distributed the vertical load that was kept constant as $0.75 \mathrm{MPa}$ during the test. The lateral load was applied to the height of every floor by three MTS 


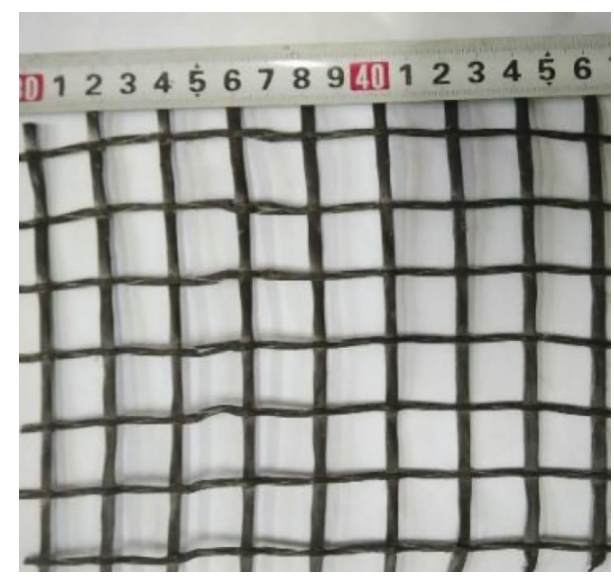

FIgURE 2: CFRP grid.

Table 1: Properties of CFRP grid, CFRP sheet, and epoxy resin from manufacturers.

\begin{tabular}{lccc}
\hline Materials & $\begin{array}{c}\text { CFRP } \\
\text { grid }\end{array}$ & $\begin{array}{c}\text { CFRP } \\
\text { sheet }\end{array}$ & $\begin{array}{c}\text { Epoxy } \\
\text { resin }\end{array}$ \\
\hline Tensile strength $(\mathrm{MPa})$ & 4300 & 4153 & 30 \\
Young's modulus $(\mathrm{GPa})$ & 240 & 242 & 4.5 \\
Thickness (mm) & 0.3 & 0.167 & - \\
Rupture Longitude & 1.49 & 1.72 & - \\
strain $(\%) \quad$ Latitude & 1.50 & - & - \\
The weight of per & 80 & - & - \\
square meter $\left(\mathrm{g} / \mathrm{m}^{2}\right)$ & & & \\
\hline
\end{tabular}

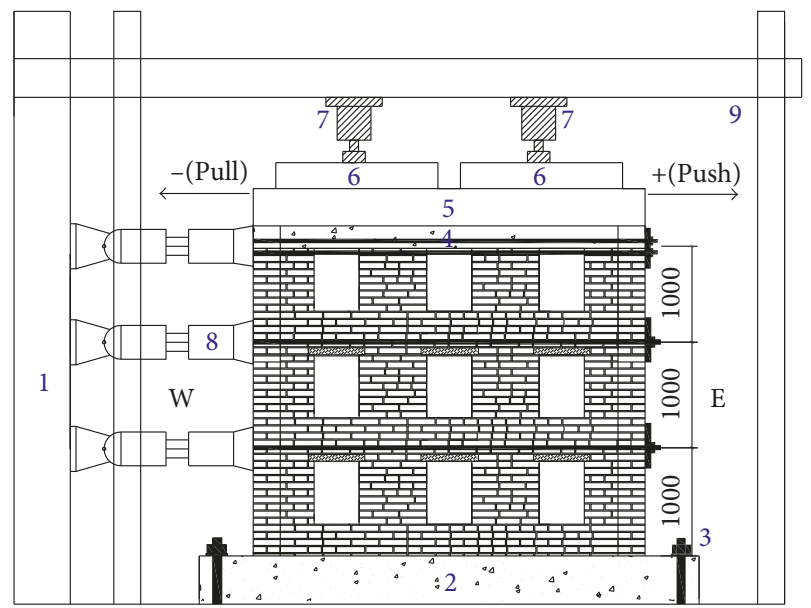

Figure 3: Test setup: (1) reaction wall, (2) RC bottom beam, (3) threaded rods, (4) RC head beam, (5) loading beam, (6) distribution beam, (7) load jacks, (8) MTS actuators, and (9) loading frame.

electrohydraulic servo actuators. The top actuator was set as the master unit, and the rest two actuators were the slave units. In order to achieve a triangular load distribution, the master unit was under displacement control and the slave units were coded to be load-controlled in accordance with the load of master unit. It means that each actuator pushed the wall with the same proportional loads at each floor as shown in Figure 4.

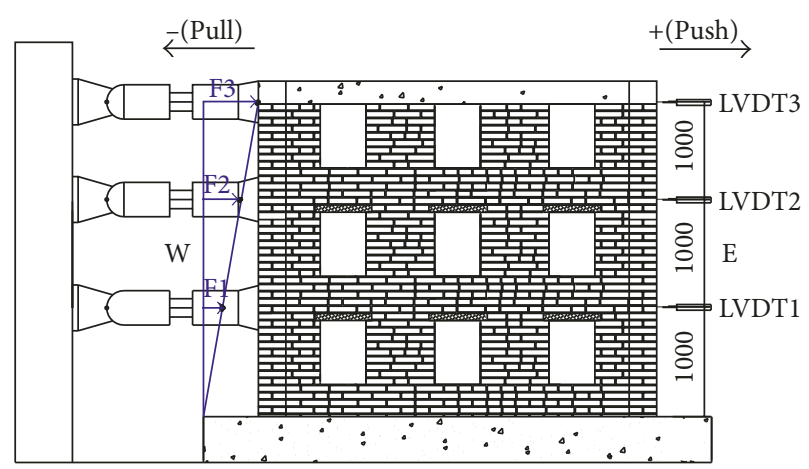

FIGURE 4: Loading scheme and instrumentations.

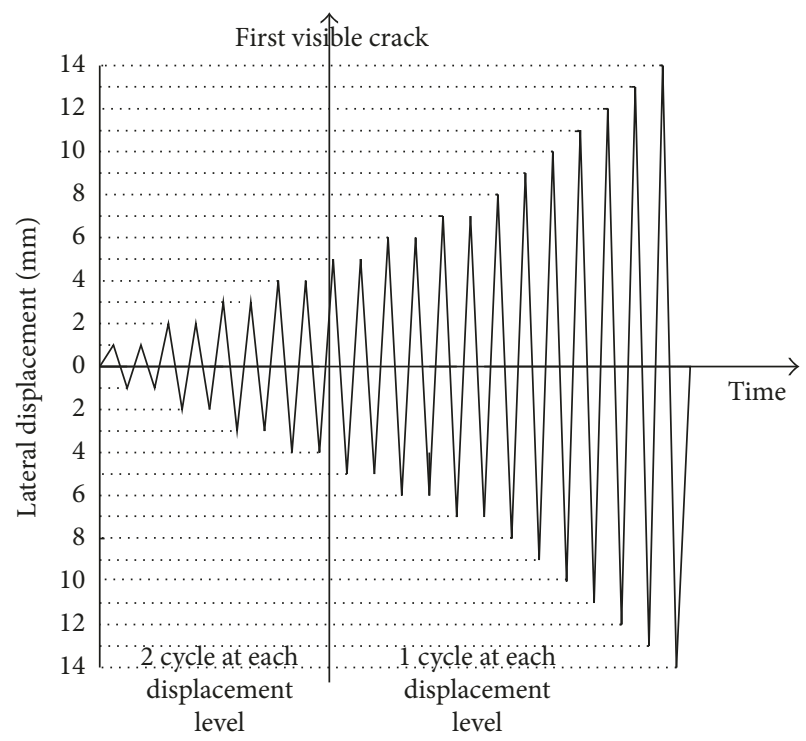

FIgURE 5: Loading history.

A typical quasistatic loading history was adopted to simulate the seismic action by a displacement-controlled loading. For the URM wall, two cycles were adopted at each displacement level prior to the appearance of first visible crack and one cycle thereafter, in which the displacement increment was $1 \mathrm{~mm}$. When the seismic shear bearing capacity of the wall decreased to $85 \%$ of the maximum load, or the wall displayed severe damages, the test was terminated. For the CRM wall, the same loading history as the URM wall was applied. The loading history is presented in Figure 5.

Three linear variable differential transformers (LVDTs) were installed to measure the lateral displacement at height of every floor. The loading scheme and instrumentation are illustrated in Figure 4.

\section{Experimental Study}

3.1. Test of URM Wall. The URM wall response under quasistatic action could be divided into three stages as follows: the elastic stage, the deformation development stage, and the strength decrease stage. The URM wall showed elastic response of lateral load-displacement 


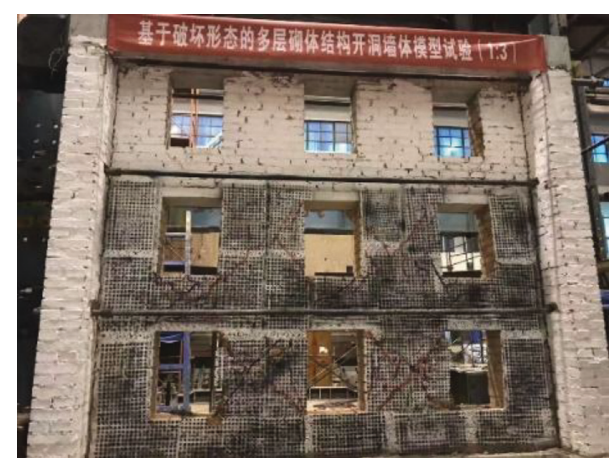

(a)

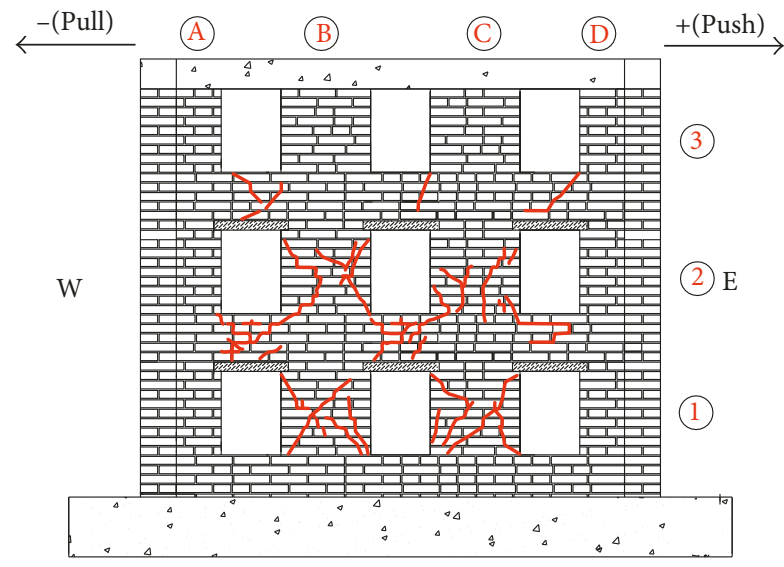

(b)

FIGURE 6: Final failure and crack pattern of the URM wall. (a) Final failure of the URM wall from the south side. (b) Crack schematic diagram of URM wall.

relationship when the top lateral displacement was below $\pm 7 \mathrm{~mm}$, indicating that it behaved the in elastic stage. There were no visible cracks observed at this stage. When the top lateral displacement reached to $\pm 7 \mathrm{~mm}$, the first visible crack appeared in the mortar layer of the 2-CD region, which was defined as the upper boundary of the elastic stage. Consequently, each displacement level was cycled once afterwards.

The corresponding top displacement range of the deformation development stage was $\pm 8 \mathrm{~mm}$ to $\pm 15 \mathrm{~mm}$. When the top lateral displacement reached to $+8 \mathrm{~mm}$, the $2-\mathrm{AB}$ and 2 -BC regions displayed cracks at the corner of first floor openings; in the meantime, new cracks occurred in the 2-CD region. When the top lateral displacement reached to $+10 \mathrm{~mm}$, the cracks of 2-AB, 2-BC, and 2-CD regions further increased and developed. Following the completion of the loading cycle at the $\pm 11 \mathrm{~mm}$, the cross diagonal cracks appeared in the 2-AB, 2-BC, and 2-CD regions. After completing the loading cycle of $\pm 12 \mathrm{~mm}$, few small cracks appeared in the $1-\mathrm{B}$ region. Following the completion of the loading cycle of $\pm 13 \mathrm{~mm}$, the 1 - $\mathrm{C}$ and 2 - $\mathrm{B}$ regions began to crack and existing cracks in the spandrels of second floor (2-AB, 2-BC, and 2-CD) widened further. When the top lateral displacement reached to $\pm 14 \mathrm{~mm}$, the 2 -C region began to crack. As the top lateral displacement increased to $\pm 15 \mathrm{~mm}$, where the URM wall reached the maximum bearing capacity, the 1-B, 1-C, 2-B, and 2-C regions showed completely connected cross diagonal cracks. Simultaneously, the 3-AB, 3-BC, and 3-CD regions started to crack. During this stage, the load increase gradually slowed down, indicating that the stiffness of URM wall decreased. The cracks of the URM wall propagated and gradually widened.

The corresponding displacement range of the strength decrease stage was between $\pm 16 \mathrm{~mm}$ and $\pm 21 \mathrm{~mm}$. During this stage, new cracks appeared in the damaged regions, the existing cracks became intensified, and bricks at the bottom corners of the first floor openings crushed. When the top lateral displacement reached to $\pm 21 \mathrm{~mm}$, the loading capacity of the URM wall reduced to $85 \%$ of the peak load, and the test was terminated.

The final failure mode and cracking schematic diagram of the URM wall are presented in Figure 6. The cracks in the spandrels of the second floor firstly occurred, the piers of the first floor cracked thereafter, and the piers of the second floor then cracked, the spandrels of the third floor finally cracked. The failure mechanism of the URM wall was thus the weak spandrel failure corresponding to the sequence of cracking [1]. The URM wall failed due to shear failure in accordance with the cross diagonal cracks.

3.2. URM Wall Repairing. In order to develop an effective and convenient repair scheme for the earthquake damaged masonry walls, the damage mechanism and the magnitude of damage of the URM wall were the key parameters to be considered. The purpose of the present study is to evaluate the seismic performance and recovery results of the CRM wall which utilize limited CFRP grid. Therefore, only the severely damaged areas, including the spandrels of second floor and the piers of the first floor, were repaired with CFRP gird in the present study. It was expected to address the lower limit of repairing demand and its performance. Additionally, although double-side strengthening is usually recommended in the available design codes, like $[25,26]$, a single side repair scheme was adopted in the present study with consideration of the application convenience and less interruption.

The repair procedure of the earthquake-damaged masonry wall could be summarized as follows: the broken bricks and mortar were firstly remedied using same strength mortar, but the completely broken bricks need to be replaced using same bricks. The surface of the repair areas were then cleaned to remove the irregularities and dust after the repaired mortar being hardened. In order to secure the performance of the CFRP grid repair scheme and prevent the premature cutting fracture of the CFRP grids, CFRP sheets were bonded at the edges of openings before bonding CFRP grids as presented in Figure 7. The CFRP sheet width was $100 \mathrm{~mm}$, and the fiber direction was across the edges. The epoxy resin was only applied to the repaired area, and the CFRP grids were then bonded. The CFRP grid repairing system was cured for 24 hours before testing. The repaired masonry wall is schematically presented in Figure 7. 


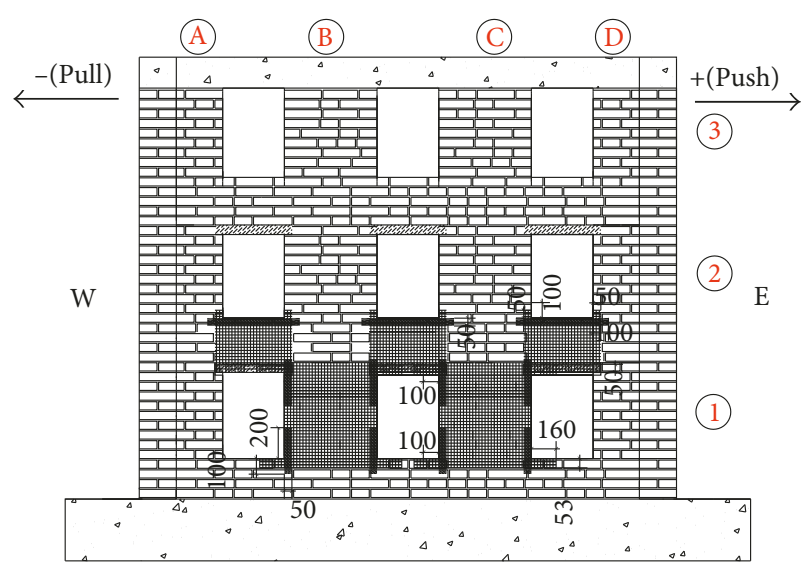

FIgURE 7: Repair scheme of the damaged URM wall.

3.3. Test of CRM Wall. The failure process of the CRM wall could be divided to three stages: the predamage minor development stage, the new damage development stage, and the strength decrease stage. When the top lateral displacement was below $\pm 6 \mathrm{~mm}$, the residual displacement was quite small after unloading. When the top lateral displacement reached to the first cycle of $+3 \mathrm{~mm}$, the breakage sound of the hardened epoxy resin could be heard. It can be attributed to the development of the existing cracks. When the top lateral displacement continuously increased, no apparent cracks occurred or widened, whereas the epoxy resin fracture sound could be occasionally heard. When the top lateral displacement reached to $\pm 6 \mathrm{~mm}$, the 1 -A region displayed new cracks, implying the limit of predamage minor development stage.

The corresponding displacement range of the new damage development stage was $\pm 7 \mathrm{~mm}$ to $\pm 22 \mathrm{~mm}$. Following the completion of the first loading cycle at the $\pm 7 \mathrm{~mm}$, the CFRP grid near the center of $1-\mathrm{C}$ region debonded, and the existing cracks in this region widened. The lateral load was turned to single cycle at each load level thereafter to match with the loading history of URM wall. When the top lateral displacement reached to $\pm 8 \mathrm{~mm}$, the $1-\mathrm{D}$ region displayed new cracks, the CFRP grid at the center of 1-B region simultaneously debonded, and the existing cracks of this region widened as consequence. With the top lateral displacement reaching to $\pm 9 \mathrm{~mm}$, the CFRP grid of the $2-\mathrm{AB}$ region started to debond, and the cracks of this region widened. As the top lateral displacement reaching to $\pm 10 \mathrm{~mm}$, the 2 -CD and 2 - $\mathrm{A}$ regions showed new cracks. In the meantime, the CFRP grid near the center of 2-CD region debonded. While the top lateral displacement reached to $\pm 11 \mathrm{~mm}$, the cross diagonal cracks of the 1-B and 1-C regions became apparently widened, the 1-A and 1-D regions displayed fully connected cross diagonal cracks. When the top lateral displacement increased to $\pm 15 \mathrm{~mm}$, the CFRP grid at the center of $2-\mathrm{BC}$ region started to debond, and the existing cracks in the region widened. Until this lateral displacement level, all five repaired areas exhibited debonding failures. As the top lateral displacement continuously increased, the existing cracks widened with the appearance of new cracks and the CFRP grid gradually debonded from the masonry. With the top lateral displacement reaching to $\pm 20 \mathrm{~mm}$, the CRM wall reached the negative maximum bearing capacity with the widening of the 3-AB, 3-BC, and 3-CD regions existing cracks. After completion of the loading cycle at the $\pm 22 \mathrm{~mm}$, all existing cracks became wider and all CFRP grids partly debonded from the masonry. The CRM wall achieved the positive maximum bearing capacity at this load level as well.

The corresponding displacement range of the strength decrease stage was $\pm 23 \mathrm{~mm}$ to $\pm 28 \mathrm{~mm}$. At this stage, the cracks developed along with some mortar and broken bricks on the repairing areas falling off. The spandrels of the first floor showed a large shear deformation. Following the completion of the loading cycle at the $\pm 28 \mathrm{~mm}$, all CFRP grids dramatically debonded, and the unrepaired areas were severely damaged. Meanwhile, the lateral load of the CRM wall reduced to $85 \%$ of the peak load, and the test was terminated accordingly.

The final failure and cracking schematic diagram of the CRM wall are presented in Figure 8. The details of failure were shown in Figure 9. The debonding failure mostly initiated from the center of repaired regions and propagated to the edges. It was noticed that the CFRP gird was not fully debonded from the masonry because the additional CFRP sheets bonded at the edges of openings which can effectively prevent the propagation of debonding failure. It may be concluded that the failures of the CRM wall developed from the lower floor to the higher floor according to the sequence of failure. Furthermore, the unrepaired areas cracked before the occurrence of debonding failure of the same floor.

\section{Discussion}

In this section, the seismic performance of the model wall prior to and after repairing was quantitatively analyzed. The effectiveness of the adopted repair scheme was evaluated based on the experimental results.

4.1. Failure Mechanism. In the present study, the URM wall under the in-plane quasistatic loading failed in the sheardominant failure mode, which was mainly characterized by the cross diagonal cracks occurred in both spandrels and piers. Also, the failure mechanism was considered as a typical weak spandrel failure because the spandrels of second floor cracked before the occurrence of cracks in piers of the first floor.

The repairing mechanism of FRP grid mainly takes the advantages of high tensile strength and Young's modulus of fiber, which can effectively prevent the occurrence of cracks. Furthermore, the bonded FRP crossing the local cracks contributes bridge effects to secure the structure stability and integrity and to restrain the global deformation. The bidirectional fiber structure of the grid is more effective to restrict the diagonal shear crack failure [22, 27, 28].

It needs to be stressed that the failure of CRM wall was largely affected by the magnitude of damage and repair scheme $[13,19]$. The failure of CRM wall in the present study consisted of the CFRP grid debonding failure and shear diagonal cracks in the unrepaired masonry areas. The sequence of CRM wall failure strongly depended on 


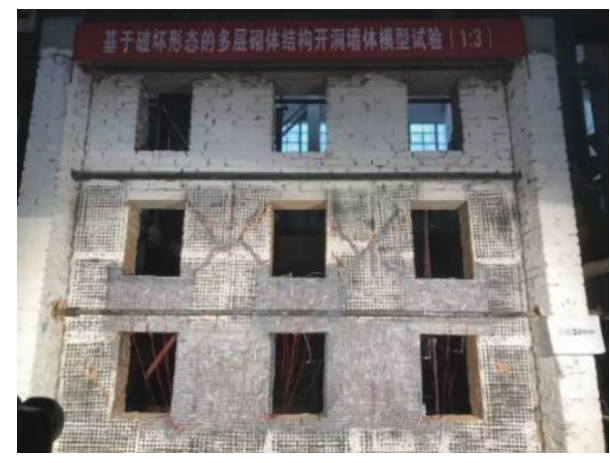

(a)

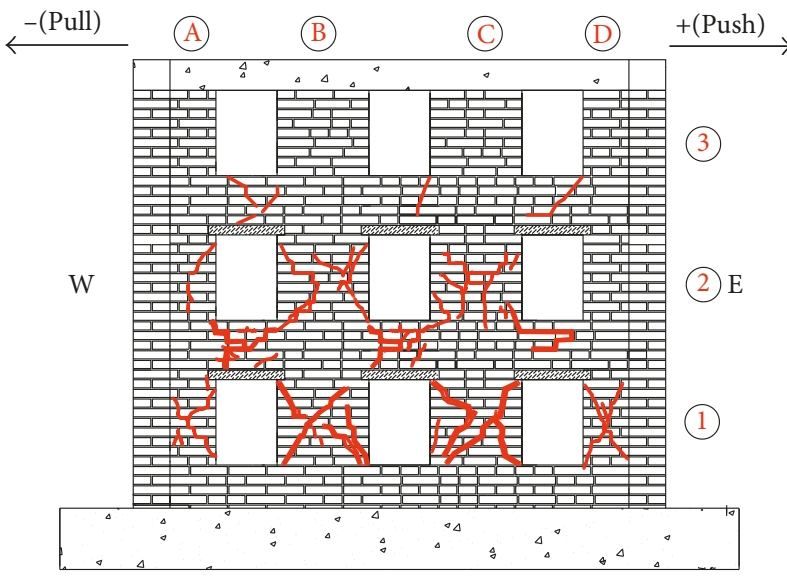

(b)

FIGURE 8: Final failure and crack pattern of CRM wall. (a) Failure of the CRM wall from the south side. (b) Crack schematic diagram of CRM wall.

the magnitude of damage, extent of damage, and repair scheme. The unrepaired piers of the first floor cracked prior to the debonding failure of repaired piers at the same floor, indicating that the failure mechanism shifted from the weak spandrel failure to the weak pier failure due to the application of CFRP grids. The weak pier failure is the preference because it rarely leads to the collapse of the entire wall compared with the weak spandrel failure $[1,7]$. Also, the reason why no fiber fracture occurred may be due to the weaker strengthening. The failure mode usually corresponding to strong strengthening, like fiber fracture, is the preference because the advantages of high strength of FRP can be fully utilized.

4.2. Hysteretic Response and Skeleton Curve. The hysteretic response represents the detailed relationship of lateral displacement and the corresponding load. It demonstrates the deformation characteristics, the stiffness degradation, and the energy dissipation of the structures during cyclic load. The hysteretic and skeleton curves of each floor of the model wall prior to and after repairing are presented in Figures 10 and 11.

From the comparison of the hysteretic and skeleton curves of the model wall at each floor, it can be found that the seismic shear bearing capacity of the URM wall was $235.7 \mathrm{kN}$. It was effectively restored to $194.3 \mathrm{kN}$ after CFRP grids repairing. The shear bearing capacity of was restored to

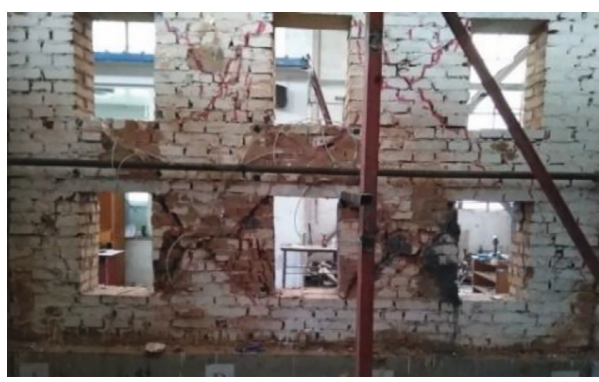

(a)

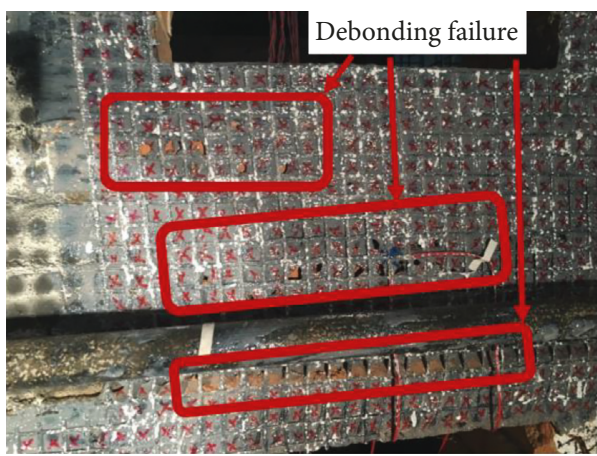

(b)

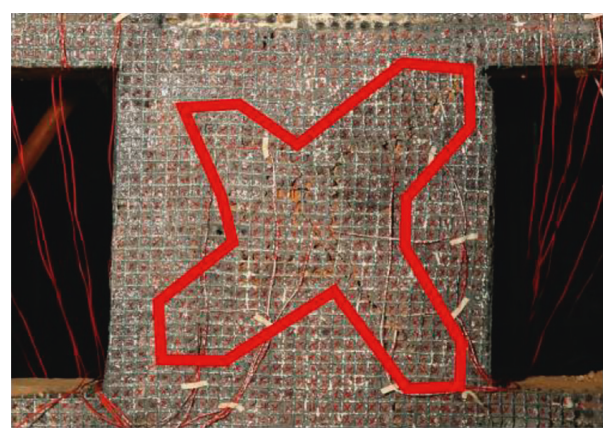

(c)

FIGURE 9: Failure details of CRM wall. (a) Failure of the CRM wall from the north side. (b) Debonding failure in 2-CD region. (c) Debonding failure in 1-B region.

$82.4 \%, 84.7 \%$, and $83.0 \%$ for the first, second, and third floor, respectively. The hysteresis curves of the URM wall displayed a certain pinching phenomenon, whereas the CRM wall curves exhibited fatter envelope curve, demonstrating an improved energy dissipation capacity. Due to the heavy damage of the URM wall and the limited repair areas, the secant stiffness of the CRM wall did not recover to the undamaged state as shown in Figure 11(b).

4.3. Stiffness Degradation. The secant stiffness of the model wall is expressed by

$$
K_{i}=\frac{\left|+F_{\max , i}\right|+\left|-F_{\max , i}\right|}{\left|+x_{\max , i}\right|+\left|-x_{\max , i}\right|},
$$

where $\left| \pm F_{\max , i}\right|$ is the absolute value of the positive and negative peak lateral loads of the $i$ th cycle, and $\left| \pm x_{\max , i}\right|$ is the absolute value of displacements corresponding to the 


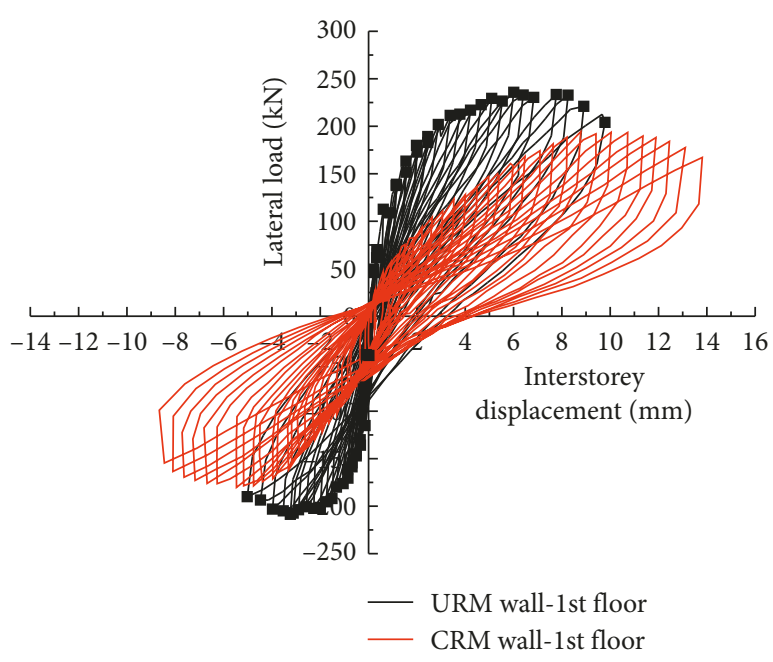

(a)

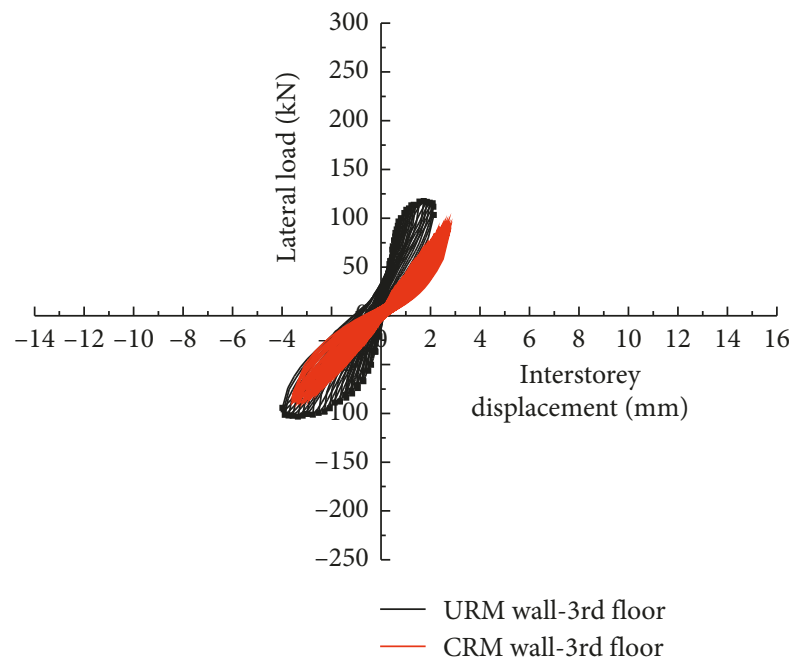

(c)

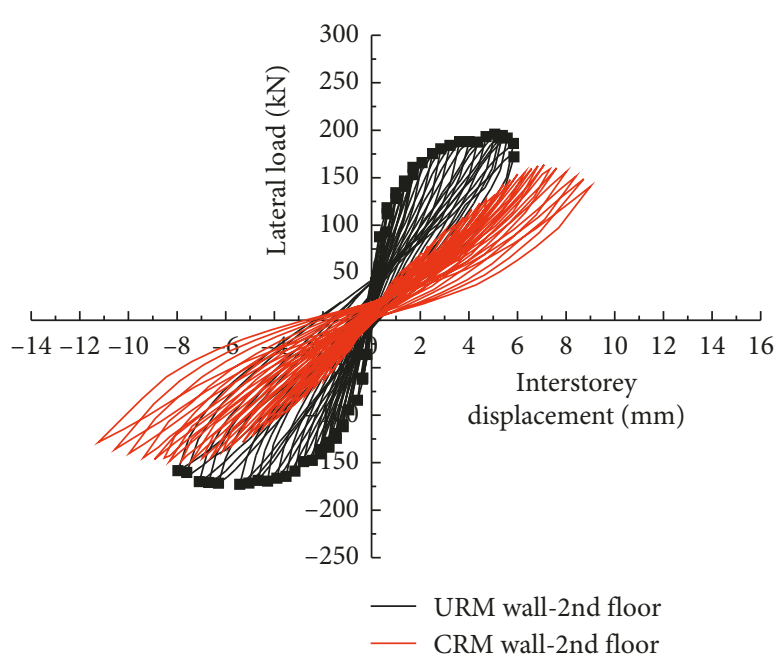

(b)

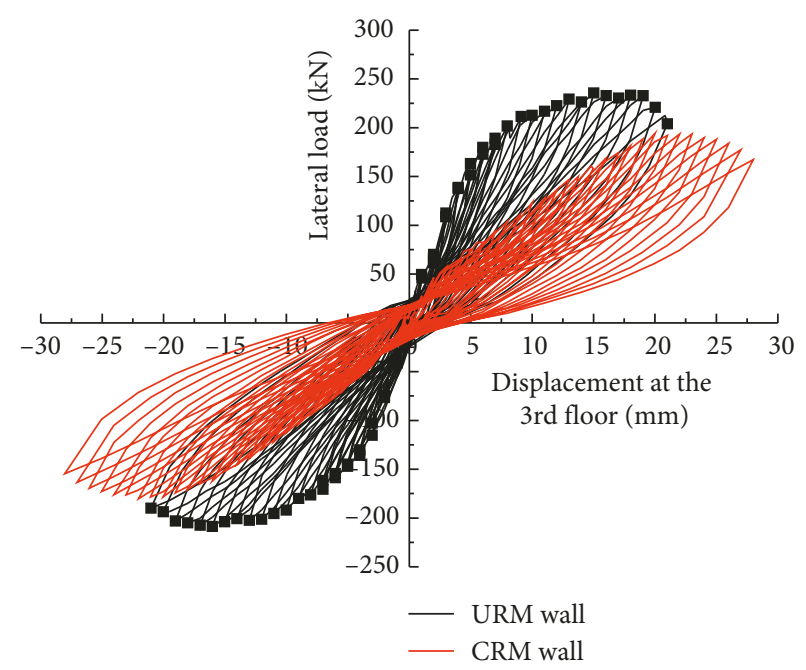

(d)

FIgURE 10: Hysteresis curves of the URM and CRM walls. (a) Hysteresis curves of 1st the floor. (b) Hysteresis curves of the 2nd floor. (c) Hysteresis curves of the 3rd floor. (d) Hysteresis curves of the entire wall.

positive and negative peak lateral loads of the $i$ th cycle. In the case of two cycles prior to cracking, the stiffness was calculated by the first cycle. The stiffness degradation curves presented in Figure 12 showed that the initial secant stiffness of the CRM wall was lower than that of the URM wall. This moderate stiffness recovery can be attributed to the severe damage of URM wall and the limited repairing scheme.

For the URM wall, the stiffness degradation of the elastic stage was significantly greater than the deformation development stage. In terms of the CRM wall, prior to the first new crack occurrence $( \pm 6 \mathrm{~mm})$, the stiffness degradation of this stage was apparently greater compared to the new damage development stage. Compared to the URM wall, since the CFRP grid restricted the occurrence and development of cracks, the stiffness degradation of the CRM wall was milder than the URM wall.

4.4. Displacement Ductility. The displacement ductility of the model wall refers to the deformability of the masonry wall without significant loss of shear bearing capacity. In general, the ductility magnitude of the structure is expressed by the ductility coefficient $\mu$ which can be assessed as a ratio of displacement at the ultimate state $d_{\mathrm{u}}, 85 \%$ of peak load in the present study, to the displacement at the attained elastic limit $d_{\mathrm{y}}$, like the appearance of first crack, as.

$$
\mu=\frac{d_{\mathrm{u}}}{d_{\mathrm{y}}} \text {. }
$$

Because the initiation of cracking state of each floor of CRM wall was difficult to capture, in the present study, the displacement ductility of the entire wall was analyzed. To simplify the calculation, the method proposed by Tomaževič [29] was adopted to idealize the actual envelope load-displacement curve as an ideal elastic-plastic relationship. The idealized maximum strength $R_{\max , i}$ is evaluated by assuming the same energy dissipation capacities of the actual and idealized structure, which is the 


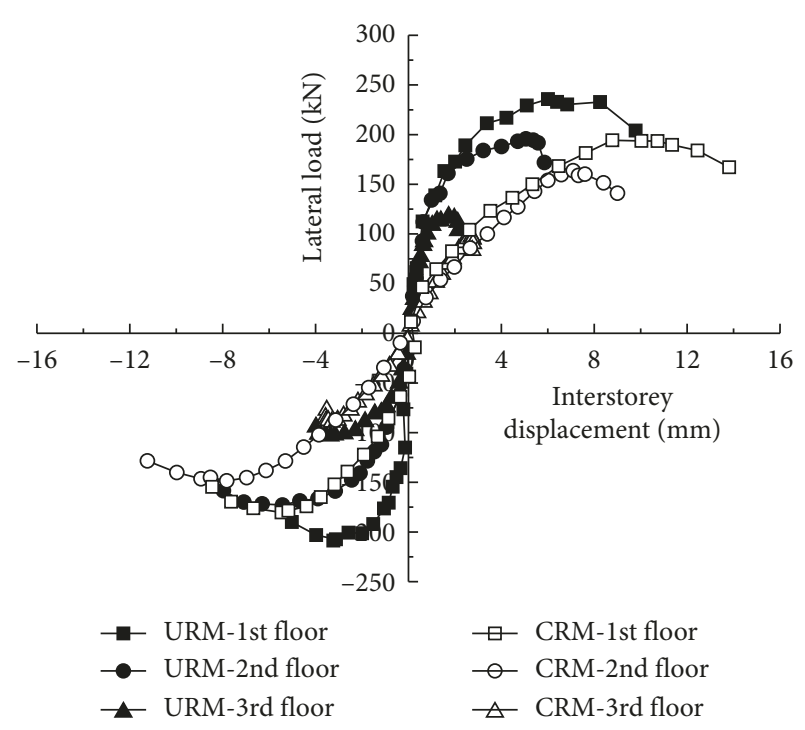

(a)

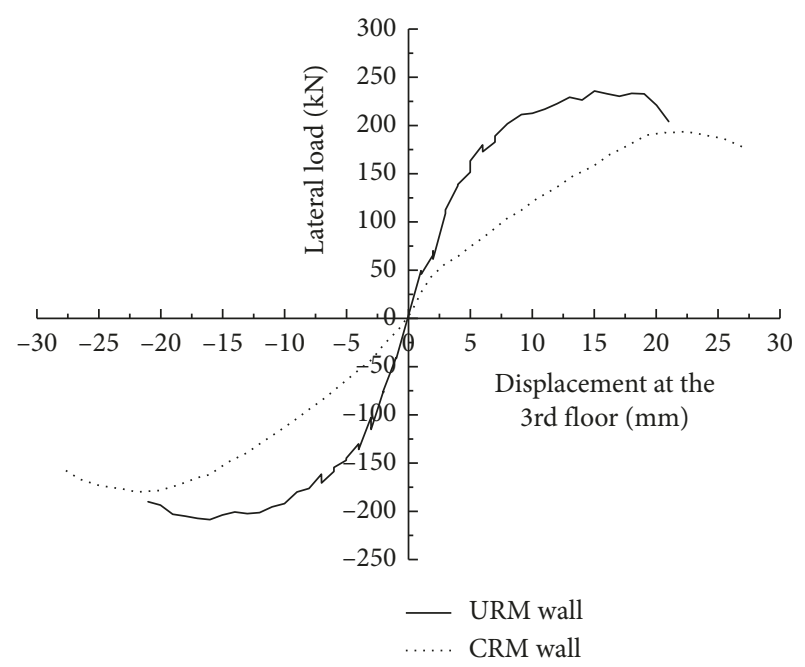

(b)

FIGURE 11: Envelope curves of URM and CRM wall. (a) Envelope curves of each floor. (b) Envelop curves of the entire wall.

area enveloped by either load-displacement curve. The secant stiffness at the formation of the first crack of the idealized curve $K_{\mathrm{e}}$ was defined as the ratio of the load to the corresponding displacement at the initiation of the cracks as

$$
K_{\mathrm{e}}=\frac{R_{\mathrm{cr}}}{d_{\mathrm{cr}}}
$$

where $R_{\mathrm{cr}}$ and $d_{\mathrm{cr}}$ are the lateral shear load and corresponding displacement at the initiation of cracks, respectively. When idealizing the actual curve, the idealized maximum lateral shear load $R_{\max , i}$ can be calculated as Tomaževič [29].

$$
R_{\max , i}=K_{\mathrm{e}}\left(d_{0.85 R_{\max }}-\sqrt{d_{0.85 R_{\max }}^{2}-\frac{2 A_{\mathrm{env}}}{K_{\mathrm{e}}}}\right),
$$

where $R_{\max , i}$ is the area enveloped by the actual loaddisplacement curve, and $d_{0.85 R_{\max }}$ is the lateral displacement

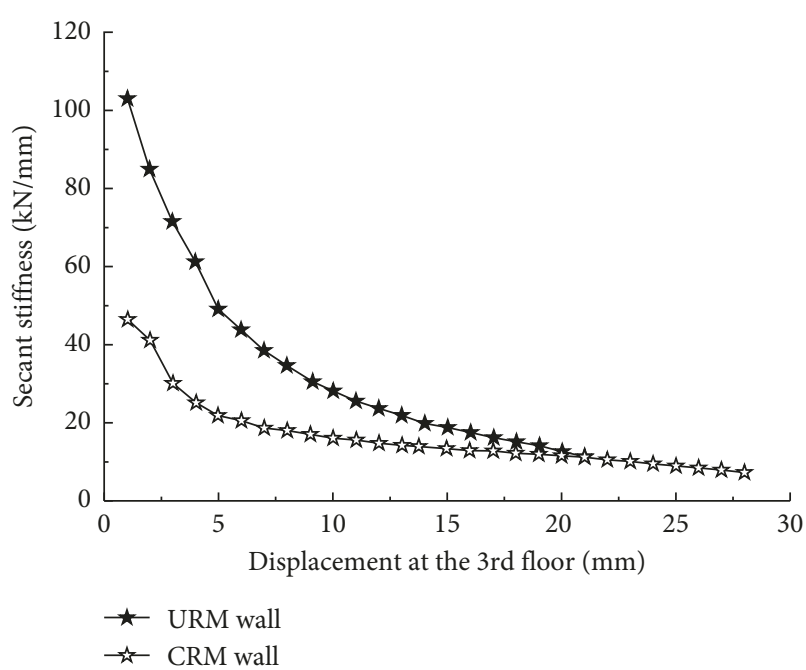

FIGURE 12: Secant stiffness degradation of URM and CRM wall.

at the ultimate state. The displacement at the idealized elastic limit thus $d_{\mathrm{e}, i}$ can be evaluated as

$$
d_{\mathrm{e}, i}=\frac{R_{\mathrm{max}, i}}{K_{\mathrm{e}}}
$$

The ductility coefficient $\mu$ can be eventually determined according to the idealized load-displacement curve as

$$
\mu=\frac{d_{0.85 R_{\max }}}{d_{\mathrm{e}, i}}
$$

The obtained idealized envelope load-displacement curves are presented in Figure 13. Consequently, the ductility coefficient of the URM wall was 2.35 , and it increased to 2.41 for the CRM wall. This promotion was because CFRP grids effectively postponed or even prevented the appearance and development of the cracks.

4.5. Energy Dissipation Capacity. The hysteretic loop area of each displacement level represented the energy dissipation of the corresponding state. Figure 14 presents the energy dissipation of each floor at every displacement level of the wall prior to and after repairing. It can be found that the energy dissipations of the walls prior to and after repairing were approximately identical before the first new crack appearance in the CRM wall when the top displacement reached to $\pm 6 \mathrm{~mm}$. The energy dissipation of the walls prior to and after repairing was mainly attributed to the first and second floors, leading to these two floors severe damaged. For the URM wall, after reaching to the peak load $( \pm 15 \mathrm{~mm})$, the energy dissipation of the first floor significantly increased compared to the second floor. For the CRM wall, when the top displacement of the CRM wall reached to $\pm 15 \mathrm{~mm}$, as all CFRP grids exhibited debonding failure, the energy dissipation of the first floor significantly increased compared to the second floor. The energy dissipations of both first and second floors of CRM wall were almost equivalent to these of the URM wall at the same displacement level, indicating that the energy dissipation capacity was successfully restored due to the CFRP grid 


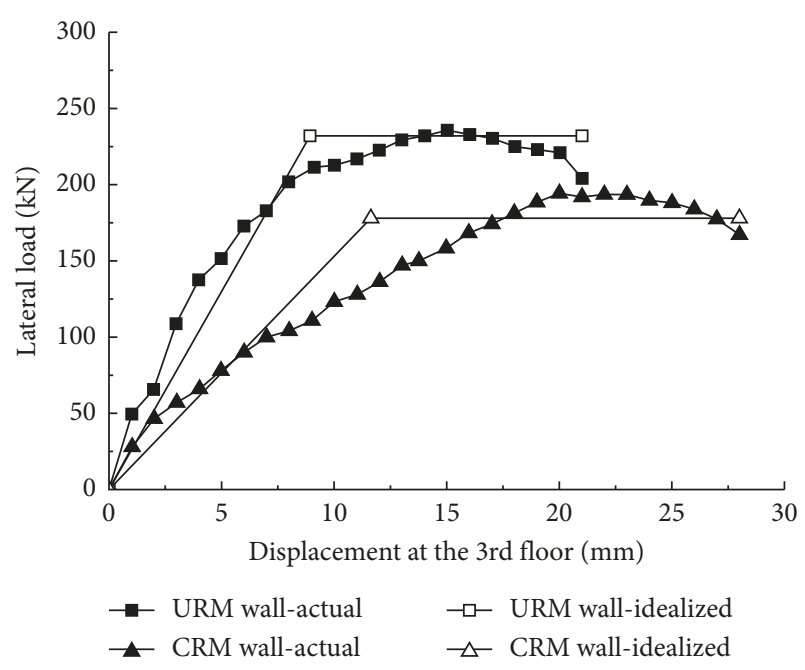

Figure 13: Actual and idealized envelop curves.

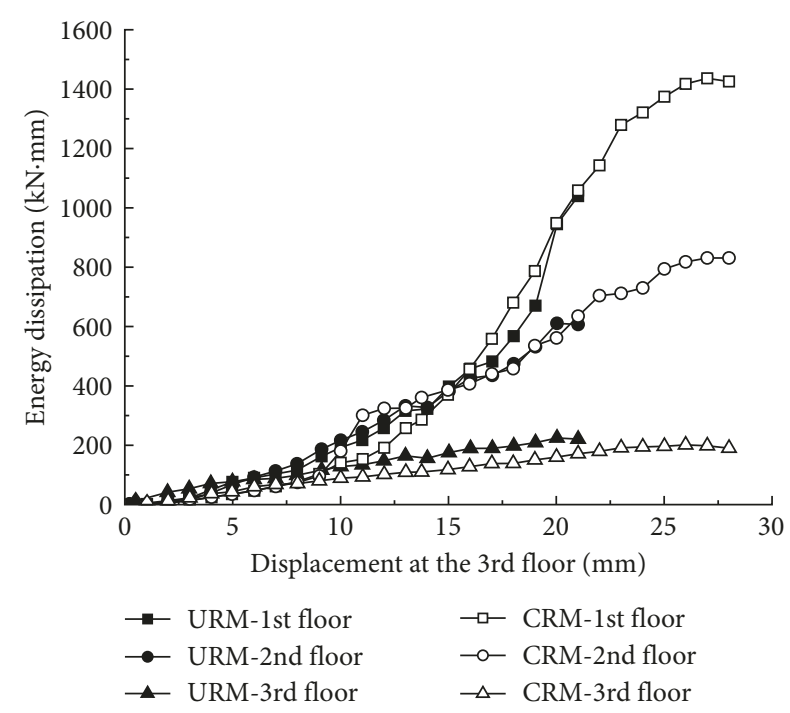

FIgURE 14: Energy dissipation of both URM and CRM wall.

repairing. However, due to the fact that the third floor was unrepaired, the corresponding energy dissipation was not restored. When the top lateral displacement of the CRM wall reached to $\pm 26 \mathrm{~mm}$, the energy dissipation of each floor started to decrease, indicating that the CFRP grid displayed severe debonding failure and the wall severely damaged.

Figure 15 shows the percentage of energy dissipation of the entire wall contributed from each floor. The development trends of the percentage of energy dissipation contributed from each floor of both URM and CRM walls were almost similar. It can be found that the percentage of energy dissipation contributed from the third floor continuously decreased. On the contrary, the percentages of energy dissipation contributed from both first and second floors constantly increased.

In terms of URM wall, once the first crack occurred $( \pm 7 \mathrm{~mm})$, the percentages of energy dissipation contributed from the first and second floors were greater than those from

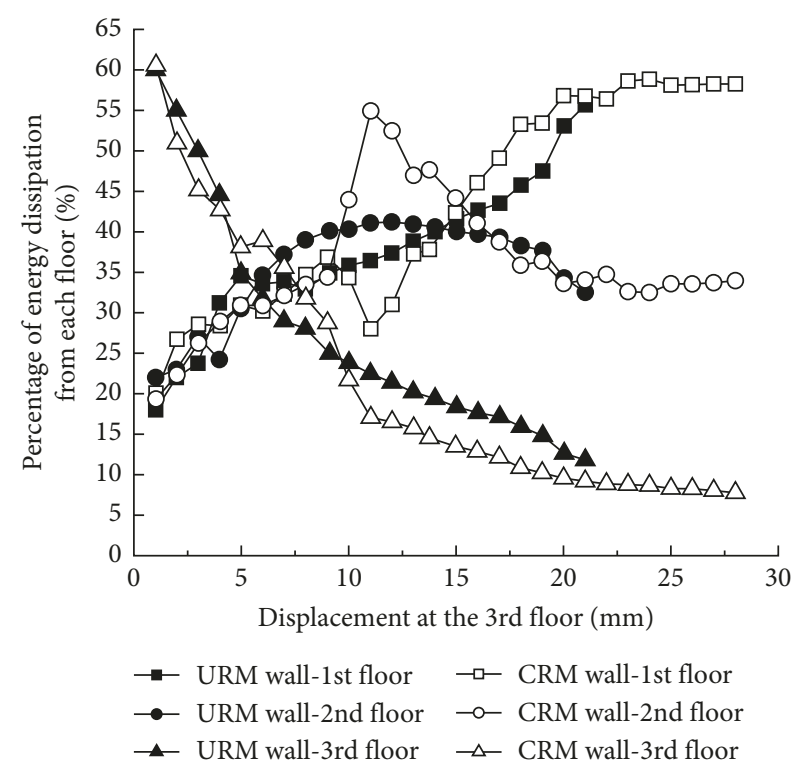

Figure 15: Percentage of energy dissipation from each floor.

the third floor because the damages intensively concentrated in the lower two floors. In the deformation development stage of the URM wall ( $\pm 8 \mathrm{~mm}$ to $\pm 15 \mathrm{~mm}$ ), the percentage of energy dissipation contributed from the second floor was greater than that from the first floor because heavy damages occurred in the spandrels of the second floor. After the peak load of the URM wall, the energy dissipation capacity of the entire wall mostly contributed from the first floor because the heavy damages shifted to the piers of the first floor.

For the CRM wall, after all repaired piers of the first floor, 1-C, and 1-B regions starting to debond ( $\pm 9 \mathrm{~mm})$, the energy dissipation capacity of entire wall mostly shifted to the second floor due to the initiation and development of debonding in the spandrels of second floor. After the top lateral deformation reaching to $\pm 15 \mathrm{~mm}$, where all repaired spandrels of second floor exhibited debonding failure, the major contributions on the energy dissipation of entire wall shifted back the first floor. After the peak load $( \pm 22 \mathrm{~mm})$, the percentages of energy dissipation contributed from each floor approximately were constant.

4.6. Interstorey Drift Rotation Angle. Interstorey drift rotation angle is another important factor to evaluate the ductility and seismic resistance of structures. Figure 16 presents the interstorey drift rotation angle of each floor of the wall prior to and after repairing. It is indicated that the interstorey drift ratio angles of the first and second floors were greater because the damages mainly occurred at these two floors. The interstorey drift rotation angles of the first and second floors of the CRM wall were almost identical as the URM wall. It is because the CFRP grid repair effectively prevented the occurrence and development of the cracks. On the contrary, the interstorey drift rotation angle of the third floor of the CRM wall was higher compared to the URM wall. Moreover, the interstorey drift rotation angle decreased 


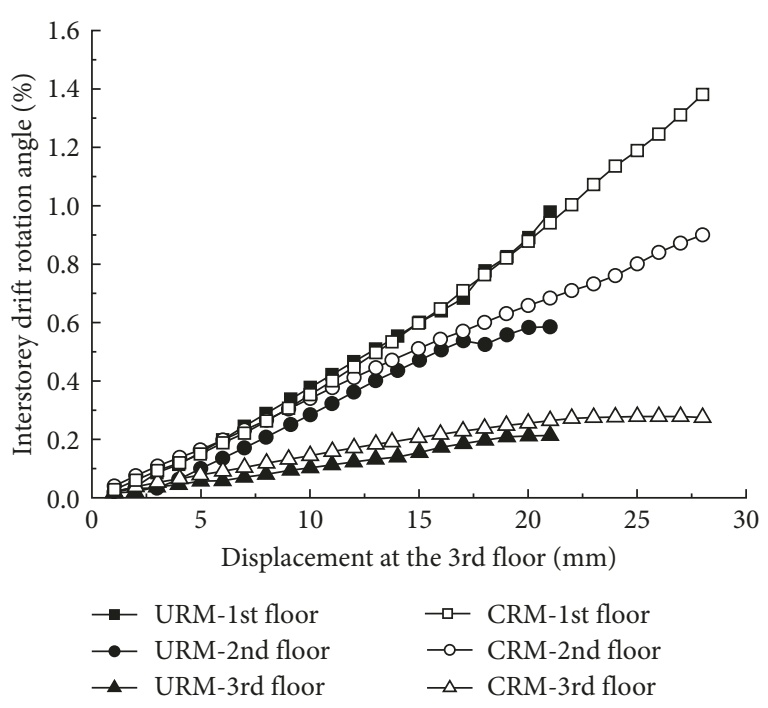

FIGURE 16: Interstorey drift rotation angle of URM and CRM wall.

from the first floor to the third floor, which implied that the CRM and URM walls were in the shear type deformation.

\section{Conclusions}

In this paper, the seismic performance of a $1 / 3$-scale threefloor masonry wall with openings prior to and after repair with CFRP grids was experimentally studied under in-plane quasistatic cyclic loading. The critical findings are as follows:

(1) In the adopted loading and boundary conditions, the model URM wall failed in weak spandrels mode. A milder CFRP gird repairing scheme was adopted in order to detect the lower limit of repairing demand. The repair scheme was determined based on the failure sequence and the magnitude of damage.

(2) It is demonstrated that the CFRP grid as a remedial technique could effectively prevent and postpone the occurrence as well as the development of cracks. The failure mode of CRM wall under the in-plane quasistatic cyclic loading consisted of the CFRP grid debonding failure and shear diagonal cracks in unrepaired masonry. The sequence of the CRM wall failure also depended on the magnitude of damage and repair scheme. The failure mechanism may shift from weak spandrel to the preferred weak pier behavior.

(3) In the present study, the seismic shear bearing capacity of the CRM wall was restored to $82.4 \%$ of the URM wall under the area-based reinforcement ratio of $17.5 \%$. The seismic resistance of masonry wall, such as ductility, deformability, and energy dissipation capacity, has effectively recovered or enhanced.

(4) The initial secant stiffness of the masonry wall was not fully recovered because of the heavy damages and limited repair areas. In order to furtherly improve the seismic performance of masonry wall, greater amount of FRP grid may be recommended.
(5) According to the findings of the present study, it is efficient to prevent the cutting fracture of FRP grids and restrain the development of debonding by bonding FRP sheet across the edges of opening.

\section{Conflicts of Interest}

The authors declare that there are no conflicts of interest regarding the publication of this paper.

\section{Acknowledgments}

The authors acknowledge the financial support received from the National Natural Science Foundation of China (51408478 and 51561135004) and China Postdoctoral Science Foundation (2015M572529) for the work reported in this paper.

\section{References}

[1] M. Tomaževič, "Seismic design of masonry structures," Progress in Structural Engineering and Materials, vol. 1, no. 1, pp. 88-95, 1997.

[2] F. M. Khalaf, A. W. Hendry, and D. R. Fairbairn, "Study of the compressive strength of blockwork masonry," ACI Structural Journal, vol. 91, no. 4, pp. 367-375, 1994.

[3] J. Heyman, The Masonry Arch, Ellis Horwood Limited Publ., Chichster, UK, 1982.

[4] S. A. Babatunde, "Review of strengthening techniques for masonry using fiber reinforced polymers," Composite Structures, vol. 161, pp. 246-255, 2017.

[5] H. Sadek and S. Lissel, "Seismic performance of masonry walls with GFRP and Geogrid Bed joint reinforcement," Construction and Building Materials, vol. 41, no. 2, pp. 977-989, 2013.

[6] G. Magenes and G. Calvi, "In-plane seismic response of brick masonry walls," Earthquake Engineering and Structural Dynamics, vol. 26, no. 11, pp. 1091-1112, 1997.

[7] Y. Belmouden and P. Lestuzzi, "An equivalent frame model for seismic analysis of masonry and reinforced concrete buildings," Construction and Building Materials, vol. 23, no. 1, pp. 40-53, 2009.

[8] M. Tomaževič, I. Klemenc, and P. Weiss, "Seismic upgrading of old masonry buildings by seismic isolation and CFRP laminates: a shaking-table study of reduced scale models," Bulletin of Earthquake Engineering, vol. 7, no. 1, pp. 293-321, 2009.

[9] M. A. ElGawady, P. Lestuzzi, and M. Badoux, "Aseismic retrofitting of unreinforced masonry walls using FRP," Composites Part B: Engineering, vol. 37, no. 2-3, pp. 148-162, 2005.

[10] M. A. ElGawady, P. Lestuzzi, and M. Badoux, "In-plane seismic response of URM walls upgraded with FRP," Journal of Composites for Construction, vol. 9, no. 6, pp. 524-535, 2005.

[11] K. M. C. Konthesingha, M. J. Masia, R. B. Petersen et al., "Experimental evaluation of static cyclic in-plane shear behavior of unreinforced masonry walls strengthened with NSM FRP strips," Journal of Composites for Construction, vol. 19, no. 3, p. 04014055, 2015.

[12] S. M. Umair, M. Numada, and K. Meguro, "Applied element method simulation of fiber reinforced polymer and polypropylene composite retrofitted masonry walls," Advances in Structural Engineering, vol. 17, no. 11, pp. 1567-1583, 2014.

[13] D. Zhou, Z. Lei, and J. Wang, "In-plane behavior of seismically damaged masonry walls repaired with external BFRP," Composite Structures, vol. 102, no. 4, pp. 9-19, 2013. 
[14] T. L. Bui, A. Si Larbi, N. Reboul et al., "Shear behaviour of masonry walls strengthened by external bonded FRP and TRC," Composite Structures, vol. 132, pp. 923-932, 2015.

[15] K. M. C. Konthesingha, M. J. Masia, R. B. Petersen et al., "Static cyclic in-plane shear response of damaged masonry walls retrofitted with NSM FRP strips-an experimental evaluation," Engineering Structures, vol. 50, no. 50, pp. 126-136, 2013.

[16] A. Mosallam and S. Banerjee, "Enhancement in in-plane shear capacity of unreinforced masonry (URM) walls strengthened with fiber reinforced polymer composites," Composites Part B: Engineering, vol. 42, no. 6, pp. 1657-1670, 2011.

[17] S. Umair, M. Numada, M. Amin et al., "Fiber reinforced polymer and polypropylene composite retrofitting technique for masonry structures," Polymers, vol. 7, no. 5, pp. 963-984, 2015.

[18] Y. Zhuge, "FRP-retrofitted URM walls under in-plane shear: review and assessment of available models," Journal of Composites for Construction, vol. 14, no. 6, pp. 743-753, 2010.

[19] H. Santa-Maria and P. Alcaino, "Repair of in-plane shear damaged masonry walls with external FRP," Construction and Building Materials, vol. 25, no. 3, pp. 1172-1180, 2011.

[20] M. Turek, C. Ventura, and S. Kuan, "In-plane shake table testing of FRP strengthened URM walls," Earthquake Spectra, vol. 23, no. 1, pp. 223-237, 2007.

[21] N. M. Ali, X. Wang, Z. Wu et al., "Basalt fiber reinforced polymer grids as an external reinforcement for reinforced concrete structures," Journal of Reinforced Plastics and Composites, vol. 34, no. 19, pp. 1615-1627, 2015.

[22] C. Papanicolaou, T. Triantafillou, and M. Lekka, "Externally bonded grids as strengthening and seismic retrofitting materials of masonry panels," Construction and Building Materials, vol. 25, no. 2, pp. 504-514, 2011.

[23] M. R. Islam, M. A. Mansur, and M. Maalej, "Shear strengthening of RC deep beams using externally bonded FRP systems," Cement and Concrete Composites, vol. 27, no. 3, pp. 413-420, 2005.

[24] GB50003-2011, Code for Design of Masonry Structures, Ministry of Construction, Beijing, China, 2011, in Chinese.

[25] CNR-DT R1/2012, Guide for the Design and Construction of Externally Bonded FRP Systems for Strengthening Existing Structures, Italian Council of Research (CNR), Rome, Italy, 2012.

[26] ACI 440.7R-10 2010, Guide for the Design and Construction of Externally Bonded Fiber-Reinforced Polymer Systems for Strengthening Unreinforced Masonry Structures, ACI Committee, Farmington Hills, MI, USA, 2010.

[27] J. G. Teng, J. F. Chen, S. T. Smith et al., FRP Strengthened RC Structures, Wiley, Chichester, UK, 2002.

[28] A. Rahman and T. Ueda, "In-plane shear performance of masonry walls after strengthening by two different frps," Journal of Composites for Construction, vol. 20, no. 5, p. 04016019, 2016.

[29] M. Tomaževič, "Damage as a measure for earthquake-resistant design of masonry structures: Slovenian experience," Canadian Journal of Civil Engineering, vol. 34, no. 11, pp. 14031412, 2007. 


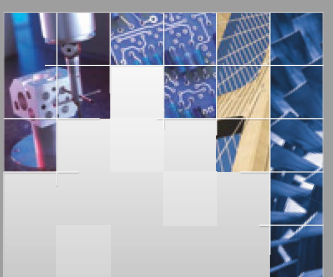

\section{Enfincering}
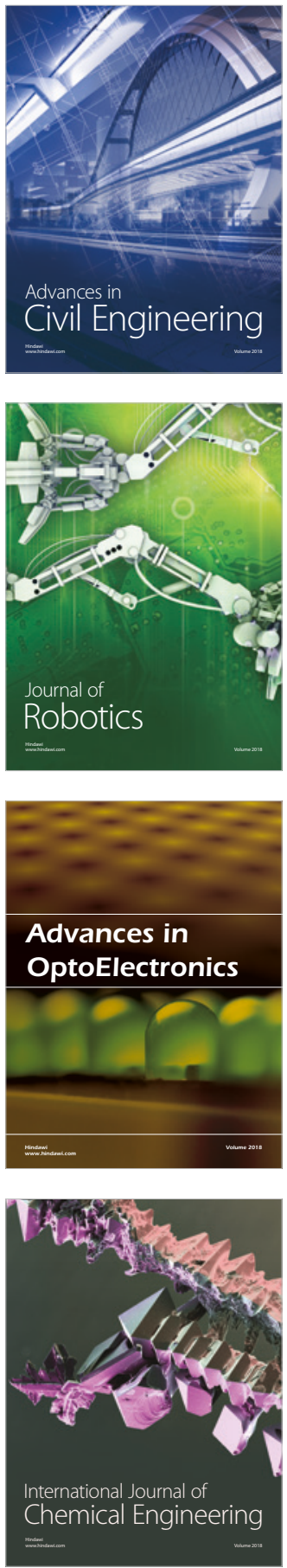

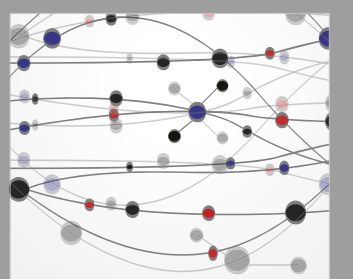

\section{Rotating \\ Machinery}

The Scientific World Journal

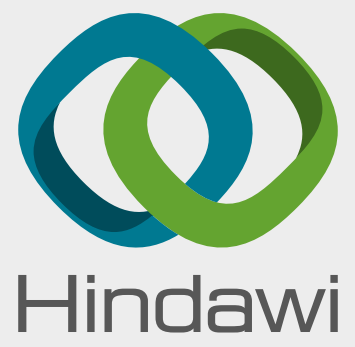

Submit your manuscripts at

www.hindawi.com
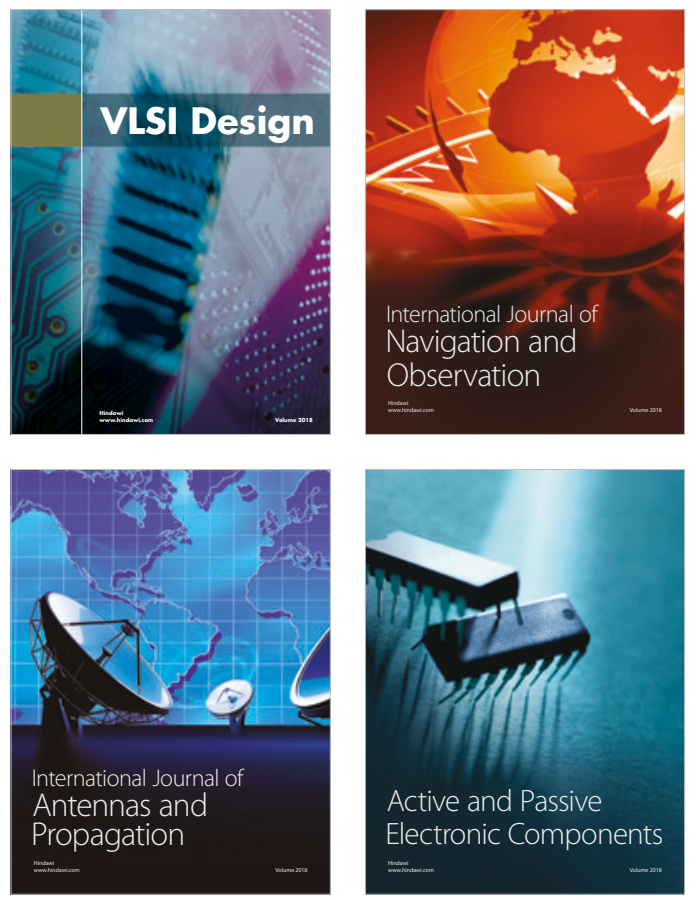
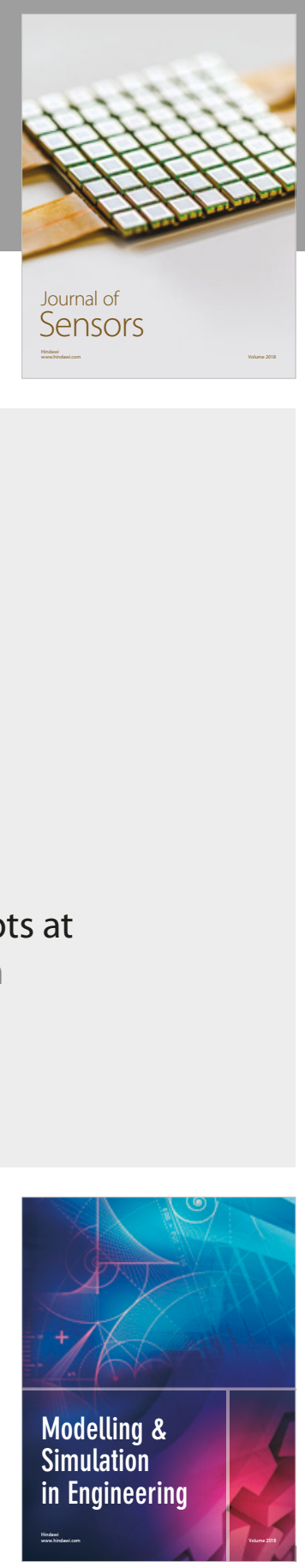

\section{Advances \\ Multimedia}
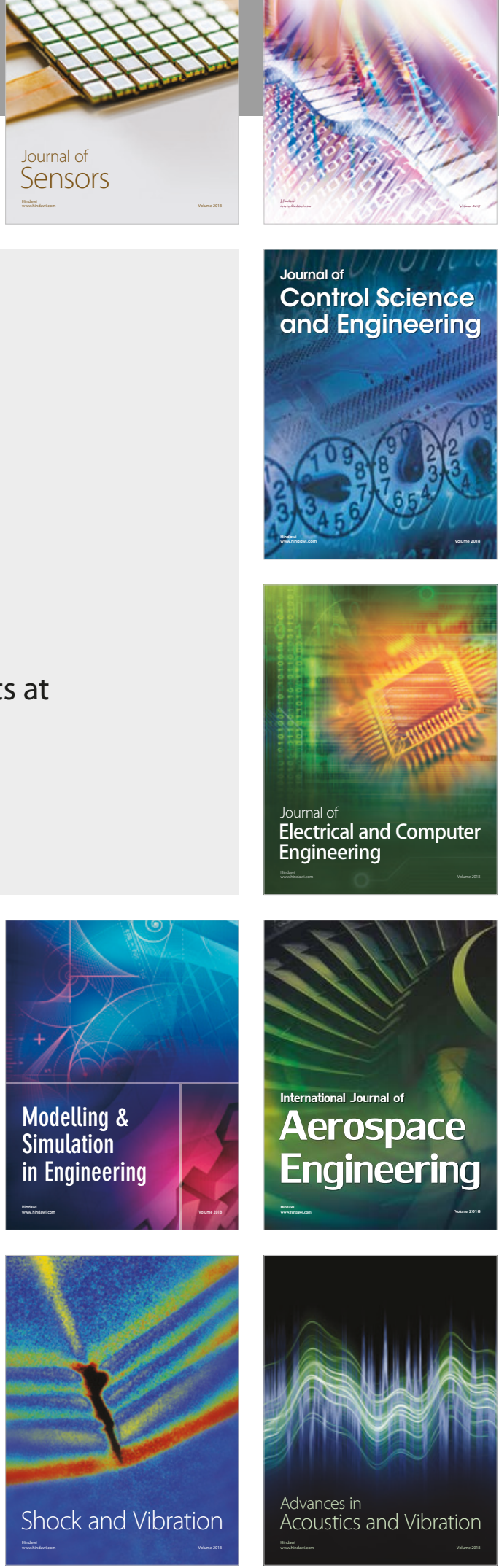